\title{
Symptoms associated with a positive result for a swab for SARS-CoV-2 infection among children in Alberta
}

\author{
James A. King MSc, Tara A. Whitten PhD, Jeffrey A. Bakal PhD, Finlay A. McAlister MD MSc
}

Cite as: CMAJ 2021 January 4;193:E1-9. doi: 10.1503/cmaj.202065; early-released November 24, 2020

See related commentary at www.cmaj.ca/lookup/doi/10.1503/cmaj.202568

\begin{abstract}
BACKGROUND: Research involving children with severe acute respiratory syndrome coronavirus 2 (SARS-CoV-2) infection has primarily focused on those presenting to emergency departments. We aimed to determine the symptoms most commonly associated with a positive result for a SARS-CoV-2 swab among community-based children.
\end{abstract}

METHODS: We conducted an observational study among children tested and followed for SARS-CoV-2 infection using nasal, nasopharyngeal, throat or other (e.g., nasopharyngeal aspirate or tracheal secretions, or unknown) swabs between Apr. 13 and Sept. 30, 2020, in Alberta. We calculated positive likelihood ratios (LRs) for self-reported symptoms and a positive SARS-CoV-2 swab result in the entire cohort and in 3 sensitivity analyses: all children with at least 1 symptom, all children tested because of contact tracing whether they were symptomatic or not and all children 5 years of age or older.

RESULTS: We analyzed results for 2463 children who underwent testing for SARS-CoV-2 infection; 1987 children had a positive result and 476 had a negative result. Of children with a positive test result for SARS-CoV-2, 714 (35.9\%) reported being asymptomatic. Although cough $(24.5 \%)$ and rhinorrhea (19.3\%) were 2 of the most common symptoms among children with SARS-CoV-2 infection, they were also common among those with negative test results and were not predictive of a positive test (positive LR 0.96, 95\% confidence interval [CI] 0.81-
1.14, and $0.87,95 \% \mathrm{Cl} 0.72-1.06$, respectively). Anosmia/ageusia (positive LR 7.33, 95\% Cl 3.03-17.76), nausea/vomiting (positive LR 5.51, 95\% Cl 1.74-17.43), headache (positive LR $2.49,95 \% \mathrm{Cl} 1.74-$ 3.57) and fever (positive LR 1.68, 95\% Cl 1.34-2.11) were the symptoms most predictive of a positive result for a SARSCoV-2 swab. The positive LR for the combination of anosmia/ageusia, nausea/ vomiting and headache was $65.92(95 \% \mathrm{Cl}$ 49.48-91.92).

INTERPRETATION: About two-thirds of the children who tested positive for SARS-CoV-2 infection reported symptoms. The symptoms most strongly associated with a positive SARS-CoV-2 swab result were anosmia/ageusia, nausea/ vomiting, headache and fever.
$\mathrm{T}$ he refrain that "children are not small adults" certainly seems to apply in the context of coronavirus disease 2019 (COVID-19). Children are less likely to become infected with severe acute respiratory syndrome coronavirus 2 (SARS-CoV-2) than adults and seem to experience less severe symptoms and have better prognoses. ${ }^{1-4}$ However, some studies have suggested that reduced disease severity in children leads to them being less likely to undergo testing. ${ }^{5}$ Three 2020 studies highlighted that COVID-19 symptoms in children are similar to those of other acute respiratory illnesses, with fever, cough, nasal congestion, fatigue and runny nose predominating. ${ }^{6-8}$ On Sept. 15, 2020, the Centers for Disease Control and Prevention reported death to be an uncommon outcome in people younger than 21 years of age $(0.08 \%$ of all deaths). ${ }^{9}$

Beyond an understanding of what symptoms most commonly present in children, health care professionals and public health policy-makers could benefit from knowing which presenting symptoms are most likely to be associated with SARS-CoV-2 infection. Many jurisdictions have implemented screening questionnaires for pediatric-dominated settings such as schools. We hypothesized that some symptoms in children are more likely than others to be associated with a positive result for a test for SARS-CoV-2. We therefore assessed symptom patterns among children in Alberta who were followed by Alberta Public Health and who had swabs taken for possible SARS-CoV-2 infection, 
comparing those with positive results and those with negative results to estimate symptom frequencies and prognostic import of symptoms in a large cohort and in 3 subgroups.

\section{Methods}

\section{Study population}

We designed an observational study of children tested for SARSCoV-2 between Apr. 13 and Sept. 30, 2020, in Alberta, a Canadian province in which health care services such as hospital care, visits to the emergency department, outpatient visits and screening tests for disease are publicly funded without user fees. The first case of reported SARS-CoV-2 infection in Alberta was on Mar. 5, 2020; however, before Apr. 13, 2020, testing was restricted to returning travellers, those being investigated as part of known outbreaks or those being admitted to hospital.

As of Apr. 13, 2020, any resident of Alberta who was symptomatic or deemed by Alberta Public Health to have had an exposure to a known case (contact tracing) was permitted to be tested. For this study, we included all pediatric patients ( $<18 \mathrm{yr}$ ) who had a positive result for a swab for SARS-CoV-2 infection or were tested because they were part of a high-risk group (e.g., close contact with a known case or within an outbreak setting) between Apr. 13 and Sept. 30, 2020. As some patients were tested several times during the study period, we included the data from their first test only, regardless of result, and excluded patients who had a previous SARS-CoV-2 test before Apr. 13, 2020. Tests were based on reverse transcription-polymerase chain reaction (RTPCR) swabs (either nasal, nasopharyngeal, throat, or other [e.g., nasopharyngeal aspirate or tracheal secretions or unknown]).

\section{Data sources}

We used the Alberta Health Services Communicable Disease Outbreak Management (CDOM) database for this study. Demographic and symptom data were collected systematically based on selfreporting by patients or parents and legal guardians of patients through standardized COVID-19 reporting forms and recorded by Alberta Public Health nurses and volunteer medical students. These data were entered into CDOM. The variables we analyzed in this study were mandatory fields in the reporting form and, therefore, no data were missing. We linked the Alberta Provincial Laboratory data (which records results of testing for SARS-CoV-2) and CDOM databases using the patient's unique lifetime identifier and analyzed CDOM records created within 5 days of the specimen collection date only. The CDOM database specifically tracks communicable disease cases and their contacts, thus, children who presented to a testing site because of symptoms but had a negative swab result were not contacted by Alberta Public Health to have the complete symptom questionnaire collected.

The standardized interview asked patients to report the presence or absence of the following symptoms: arthralgia and/or myalgia; chest pain; fever and/or fevered chills (this was subjective; actual body temperature was not measured by data collectors); conjunctivitis; cough; decreased appetite and/or anorexia; diarrhea; headache; malaise; nasal congestion; nausea and/or vomiting; rhinorrhea; shortness of breath or difficulty breathing; sneezing; sore throat; or other. If "other" was checked, any symptoms reported by patients or their caregivers but not on the standardized list were recorded in a free text field. We searched this free text field for reference to altered taste (i.e., ageusia, dysgeusia, hypogeusia, metallic or changed taste) or smell (i.e., anosmia, smell) and fatigue (i.e., exhausted, exhaustion, tired, lethargy, lethargic or energy), using a combination matching the word sound and setting a threshold for the generalized edit distance, implemented in SAS software. Sound matching used the Soundex function. ${ }^{10}$ The generalized edit distance is a generalization of the Levenshtein edit distance, using the COMPGED function in SAS. Records flagged in this way were then manually reviewed independently in duplicate by 2 authors (J.A.K. and T.A.W.) without knowledge of the patients' swab test result, and any disagreements were resolved through discussion until concurrence. On Aug. 15, 2020, anosmia/ageusia was added to the standardized questionnaire; for our analysis, we grouped any self-reported alteration in taste or smell under anosmia/ageusia (the change in symptom frequency over time for each symptom is reported in Appendix 1, Figure S1, available at www.cmaj.ca/lookup/doi/10.1503/cmaj.202065/tab-related-content). A priori, we subdivided age into $0-4,5-12$ and $13-17$ years to capture preschool, elementary and adolescent stages.

\section{Statistical analysis}

We examined symptom frequencies and prognostic import in all children followed by Alberta Public Health who had swabs done for SARS-CoV-2 infection, as well as 3 subgroups: all children with at least 1 symptom who were tested for SARS-CoV-2 infection, all children tested for SARS-CoV-2 infection because they had a high-risk exposure and all children 5 years of age or older who were tested for SARS-CoV-2 infection (given that younger children may be less well able to describe their symptoms).

We calculated crude odds ratios (ORs) and positive likelihood ratios (LRs) for each symptom, as well as patient demographic characteristics with associated 95\% confidence intervals (Cls). Likelihood ratios were estimated as they are less likely to be influenced by the prevalence of the disease under investigation in the sample population. ${ }^{11}$ We did not calculate these statistics for predictors with expected cell counts of less than 5. To assess the effect of multiple predictors in combination on the probability of positive test results, we used the method of Spiegelhalter and Knill-Jones ${ }^{12,13}$ to calculate multivariate LRs. Briefly, this involves selecting any predictors with crude LRs of 2.0 or greater or less than or equal to 0.5 , then fitting the logs of these LRs as continuous variables in a logistic regression model of the following form:

$$
\log (\text { posttest odds })=\log (\text { pretest odds })+\sum_{i=1}^{n} \gamma_{i} \log \left(\mathrm{LR}_{i}\right)
$$

Parameter estimates from this regression are then used as "shrinkage estimates" to calculate adjusted LRs using the following equation:

$$
\log \left(\operatorname{adjusted} L R_{i}\right)=\gamma_{i} \log \left(L R_{i}\right)
$$

where $\gamma_{i}$ is the shrinkage estimate from the logistic regression for predictor $i$. Note that $\gamma_{i}$ is generally between 0 and 1 so the effect 
is to bring adjusted $\mathrm{LR}_{i}$ closer to 1 than unadjusted $\mathrm{LR}_{i}$ and this shrinkage accounts for redundancy in the predictive values of the symptoms. Overall multivariate LRs are then estimated as the product of these adjusted estimates. We calculated the $\mathrm{Cls}$ for these adjusted LRs as the 2.5th and 97.5th percentiles of a bootstrap distribution of adjusted LRs. We created the bootstrap distribution by resampling from our cohort 5000 times with replacement and calculating the adjusted LRs as above for each resampled data set. All analyses were performed using SAS ver. 9.4, R ver. 3.5.2 and the epiR package.

\section{Ethics approval}

This study was approved by the University of Alberta Research Ethics Board (Pro00101096) and analyses were performed using de-identified data.

\section{Results}

Between Apr. 8 and Oct. 5, 2020, 3474 children under the age of 18 in Alberta had a record in the CDOM database for SARS-CoV-2 surveillance (Figure 1). After we excluded those children who were missing personal identifiers $(n=17)$ or without a swab test in the provincial laboratory database $(n=205), 2264$ had a positive RT-PCR swab for SARS-CoV-2 infection; however, we excluded 277 because it was not their first test or the test was not performed within 5 days of the CDOM record date, leaving 1987 children with positive results for SARS-CoV-2 for analysis (8 [0.4\%] of whom were admitted to hospital). Of the 985 children with a negative result for a SARS-CoV-2 swab, we excluded 72 because it was not their first test and 437 because the swab test was not done within 5 days of symptom data collection, leaving 476 children with negative swab results for analysis (Figure 1). Tests were based on RT-PCR swabs (either nasal [2.1\%, $n=52]$, nasopharyngeal [25.9\%, $n=638$ ], throat [71.4\%, $n=1759$ ], other [e.g., nasopharyngeal aspirate or tracheal secretions [0.5\%, $n=$ 12] or unknown [0.1\%, $n=2])$.

\section{Symptoms predictive of a positive result for a SARS-CoV-2 swab}

The most common symptoms observed in children with a positive result for SARS-CoV-2 infection were fever or chills (25.5\%), cough $(24.5 \%)$ and rhinorrhea (19.3\%) (Table 1). Seven hundred fourteen

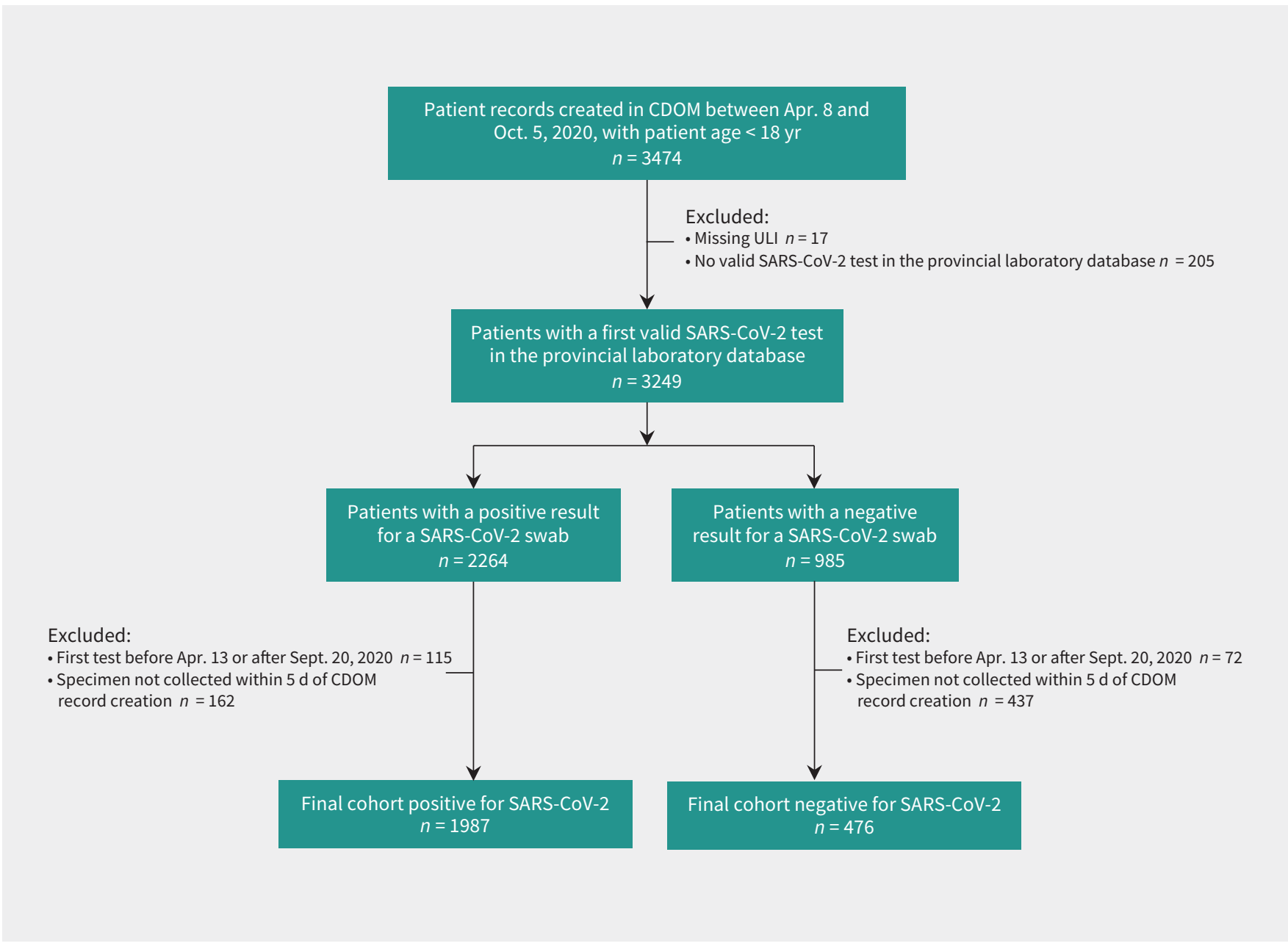

Figure 1: Flow chart for patient inclusion. We identified patients in this cohort through the Communicable Disease Outbreak Management (CDOM) database and linked them to the Alberta Provincial Laboratory database to determine when their first test for severe acute respiratory syndrome coronavirus 2 (SARS-CoV-2) occurred. Note: ULI = Unique Lifetime Identifier. 
children (35.9\%) who tested positive for SARS-CoV-2 reported being asymptomatic. The most common symptoms observed in children with a negative result for SARS-CoV-2 infection were the same as for those testing positive: cough (25.4\%), rhinorrhea $(22.1 \%)$ and fever or chills (15.1\%). Symptoms predictive of a positive test result for SARS-CoV-2 in our main analysis (Table 1) were anosmia/ageusia (positive LR 7.33, 95\% Cl 3.03-17.76), nausea/vomiting (positive LR 5.51, 95\% Cl 1.74-17.43), headache (positive LR 2.49, 95\% Cl 1.74-3.57), sneezing (positive LR 1.76, 95\% Cl 1.08-2.85), fever/chills (positive LR 1.68, 95\% Cl 1.34-2.11) and malaise (positive LR $1.58,95 \% \mathrm{Cl} 1.05-2.38$ ). None of the remaining symptoms were predictive of SARS-CoV-2 swab positivity. The positive LR for the combination of anosmia/ageusia, nausea/vomiting and headache was 65.92 (95\% Cl 49.48-91.92;
Appendix 2, Table S1, available at www.cmaj.ca/lookup/ doi/10.1503/cmaj.202065/tab-related-content).

Outside of symptom-related analyses, we did not find any sex differences in SARS-CoV-2 positivity (positive LR 0.93, 95\% Cl $0.85-1.03)$. A general trend was observed in which younger children (ages 0-4 yr) were more common in the negative cohort (positive LR $0.77,95 \% \mathrm{Cl} 0.65-0.90$ ), whereas older children (ages 13-17 yr) were more common in the positive cohort (positive LR $1.22,95 \% \mathrm{Cl} 1.04-1.42)$.

\section{Sensitivity analysis}

We found no substantial differences in the estimates when we restricted the analysis to children who had at least 1 symptom (Table 2, Figure 2). Our evaluation involving children who were

Table 1: Baseline characteristics and symptoms in children tested for severe acute respiratory syndrome coronavirus 2 infection

\begin{tabular}{|c|c|c|c|c|}
\hline Variable & $\begin{array}{c}\text { No. }(\%) \text { in patients with } \\
\text { positive SARS-CoV-2 } \\
\text { swab }{ }^{\star} \\
n=1987\end{array}$ & $\begin{array}{c}\text { No. }(\%) \text { in patients with } \\
\text { negative SARS-CoV-2 } \\
\text { swab } \\
n=476\end{array}$ & $\begin{array}{l}\text { Unadjusted OR } \\
\qquad(95 \% \mathrm{Cl})\end{array}$ & $\begin{array}{l}\text { Unadjusted positive LR } \\
\text { for SARS-CoV-2 infection } \\
\qquad(95 \% \mathrm{Cl})\end{array}$ \\
\hline \multicolumn{5}{|l|}{ Demographic characteristic } \\
\hline Age, yr; mean \pm SD & $9.3 \pm 5.2$ & $8.5 \pm 5.3$ & NA & NA \\
\hline Age $0-4$ yr & $458(23.0)$ & $143(30.0)$ & $0.70(0.56-0.87)$ & $0.77(0.65-0.90)$ \\
\hline Age 5-12 yr & $849(42.7)$ & $199(41.8)$ & $1.04(0.85-1.27)$ & $1.02(0.91-1.15)$ \\
\hline Age $13-17 \mathrm{yr}$ & $680(34.2)$ & $134(28.2)$ & $1.33(1.07-1.65)$ & $1.22(1.04-1.42)$ \\
\hline Male sex & $989(49.8)$ & $254(53.4)$ & $0.87(0.71-1.06)$ & $0.93(0.85-1.03)$ \\
\hline \multicolumn{5}{|l|}{ Symptom } \\
\hline Anosmia/ageusia & $153(7.7)$ & $5(1.1)$ & $7.86(3.21-19.26)$ & $7.33(3.03-17.76)$ \\
\hline Nausea/vomiting & $69(3.5)$ & Suppressed as count $<5$ & $5.67(1.78-18.10)$ & $5.51(1.74-17.43)$ \\
\hline Headache & $312(15.7)$ & $30(6.3)$ & $2.77(1.88-4.09)$ & $2.49(1.74-3.57)$ \\
\hline Decreased appetite/anorexia & $75(3.8)$ & $10(2.1)$ & $1.83(0.94-3.56)$ & $1.80(0.94-3.45)$ \\
\hline Sneezing & $132(6.6)$ & $18(3.8)$ & $1.81(1.09-2.99)$ & $1.76(1.08-2.85)$ \\
\hline Fever or feverish chills & $506(25.5)$ & $72(15.1)$ & $1.92(1.46-2.51)$ & $1.68(1.34-2.11)$ \\
\hline $\begin{array}{l}\text { Muscle/joint pain (myalgia, } \\
\text { arthralgia, muscular or joint } \\
\text { pain) }\end{array}$ & $56(2.8)$ & $8(1.7)$ & $1.70(0.80-3.58)$ & $1.68(0.80-3.49)$ \\
\hline Malaise & $165(8.3)$ & $25(5.3)$ & $1.63(1.06-2.52)$ & $1.58(1.05-2.38)$ \\
\hline Nasal congestion & $241(12.1)$ & $46(9.7)$ & $1.29(0.93-1.80)$ & $1.26(0.93-1.69)$ \\
\hline Fatigue & $31(1.6)$ & $6(1.3)$ & $1.24(0.51-2.99)$ & $1.24(0.52-2.95)$ \\
\hline Difficulty breathing/dyspnea & $31(1.6)$ & $6(1.3)$ & $1.24(0.51-2.99)$ & $1.24(0.52-2.95)$ \\
\hline Sore throat & $311(15.7)$ & $67(14.1)$ & $1.13(0.85-1.51)$ & $1.11(0.87-1.42)$ \\
\hline Diarrhea & $57(2.9)$ & $13(2.7)$ & $1.05(0.57-1.94)$ & $1.05(0.58-1.90)$ \\
\hline Cough & $486(24.5)$ & $121(25.4)$ & $0.95(0.75-1.20)$ & $0.96(0.81-1.14)$ \\
\hline Rhinorrhea & $383(19.3)$ & $105(22.1)$ & $0.84(0.66-1.08)$ & $0.87(0.72-1.06)$ \\
\hline Chest pain & $15(0.8)$ & Suppressed as count $<5$ & NA & NA \\
\hline Conjunctivitis & $11(0.6)$ & Suppressed as count $<5$ & NA & NA \\
\hline Asymptomatic & 714 (35.9) & $211(44.3)$ & $0.70(0.58-0.86)$ & $0.81(0.72-0.91)$ \\
\hline
\end{tabular}


tested as part of contact tracing yielded similar findings (Table 3, Figure 2). When we restricted the analysis to children 5 years of age or older we found no major differences in the estimates, although the size of the associations of some symptoms became slightly more pronounced (Appendix 3, Table S2, available at www.cmaj.ca/lookup/doi/10.1503/cmaj.202065/tab-related-content; Figure 2). We determined that the symptoms associated with a positive result for SARS-CoV-2 infection in all sensitivity analyses, as in the main analysis, were anosmia/ageusia, nausea/vomiting, headache and fever.

\section{Interpretation}

In a cohort of children being tested for SARS-CoV-2, we found that symptoms strongly associated with a positive result for a SARS-CoV-2 swab were anosmia/ageusia, nausea/vomiting, headache and fever, whereas cough, sore throat, rhinorrhea, nasal congestion or diarrhea were not. Administrators of screening questionnaires for schools or daycares may wish to consider reassessing the symptoms they screen for to include only those that are most strongly associated with positive results for swabs for SARS-CoV-2 infection. The positive LR for the 4 strongly associated symptoms were similar in all of our sensitivity analyses and thus relevant whether screening children with symptoms (such as in Table 2) or questioning those tested in the context of contact tracing (such as in Table 3).

In agreement with other studies, ${ }^{6,7,14}$ cough, fever and rhinorrhea were the most frequent symptoms in our cohort; only fever was associated with having a positive SARS-CoV-2 test result. However, the frequencies of these symptoms in our study (19\%$26 \%$ ) were lower than in studies done in hospital settings, where cough was present in $39 \%{ }^{4}$ and $49 \%{ }^{15}$ of patients, and fever in

Table 2: Baseline characteristics and symptoms in children in Alberta with at least 1 symptom who were tested for severe acute respiratory syndrome coronavirus 2 infection

\begin{tabular}{|c|c|c|c|c|}
\hline Variable & $\begin{array}{c}\text { No. }(\%) \text { in patients with } \\
\text { positive SARS-CoV-2 } \\
\text { swab* } \\
n=1273\end{array}$ & $\begin{array}{c}\text { No. }(\%) \text { in patients with } \\
\text { negative SARS-CoV-2 } \\
\text { swab* } \\
n=265\end{array}$ & $\begin{array}{l}\text { Unadjusted OR } \\
(95 \% \mathrm{CI})\end{array}$ & $\begin{array}{l}\text { Unadjusted positive LR } \\
\text { for SARS-CoV-2 } \\
\text { infection } \\
(95 \% \mathrm{Cl})\end{array}$ \\
\hline \multicolumn{5}{|l|}{ Demographic characteristic } \\
\hline Age, yr; mean \pm SD & $9.8 \pm 5.4$ & $8.4 \pm 5.3$ & NA & NA \\
\hline Age $0-4$ yr & $281(22.1)$ & $80(30.2)$ & $0.66(0.49-0.88)$ & $0.73(0.59-0.90)$ \\
\hline Age $13-17 \mathrm{yr}$ & $510(40.1)$ & $75(28.3)$ & $1.69(1.27-2.26)$ & $1.42(1.16-1.73)$ \\
\hline Male sex & $629(49.4)$ & $142(53.6)$ & $0.85(0.65-1.10)$ & $0.92(0.81-1.04)$ \\
\hline \multicolumn{5}{|l|}{ Symptom } \\
\hline Anosmia/ageusia & $153(12.0)$ & $5(1.9)$ & $7.10(2.89-17.49)$ & $6.37(2.64-15.37)$ \\
\hline Sneezing & $132(10.4)$ & $18(6.8)$ & $1.59(0.95-2.65)$ & $1.53(0.95-2.45)$ \\
\hline Fever or feverish chills & $506(39.7)$ & $72(27.2)$ & $1.77(1.32-2.37)$ & $1.46(1.19-1.80)$ \\
\hline $\begin{array}{l}\text { Muscle/joint pain (myalgia, } \\
\text { arthralgia, muscular or joint pain) }\end{array}$ & $56(4.4)$ & $8(3.0)$ & $1.48(0.70-3.14)$ & $1.46(0.70-3.02)$ \\
\hline Malaise & $165(13.0)$ & $25(9.4)$ & $1.43(0.92-2.23)$ & $1.37(0.92-2.05)$ \\
\hline Nasal congestion & $241(18.9)$ & $46(17.4)$ & $1.11(0.79-1.57)$ & $1.09(0.82-1.45)$ \\
\hline Fatigue & $31(2.4)$ & $6(2.3)$ & $1.08(0.44-2.61)$ & $1.08(0.45-2.55)$ \\
\hline Difficulty breathing/dyspnea & $31(2.4)$ & $6(2.3)$ & $1.08(0.44-2.61)$ & $1.08(0.45-2.55)$ \\
\hline Sore throat & $311(24.4)$ & $67(25.3)$ & $0.96(0.70-1.30)$ & $0.97(0.77-1.21)$ \\
\hline
\end{tabular}




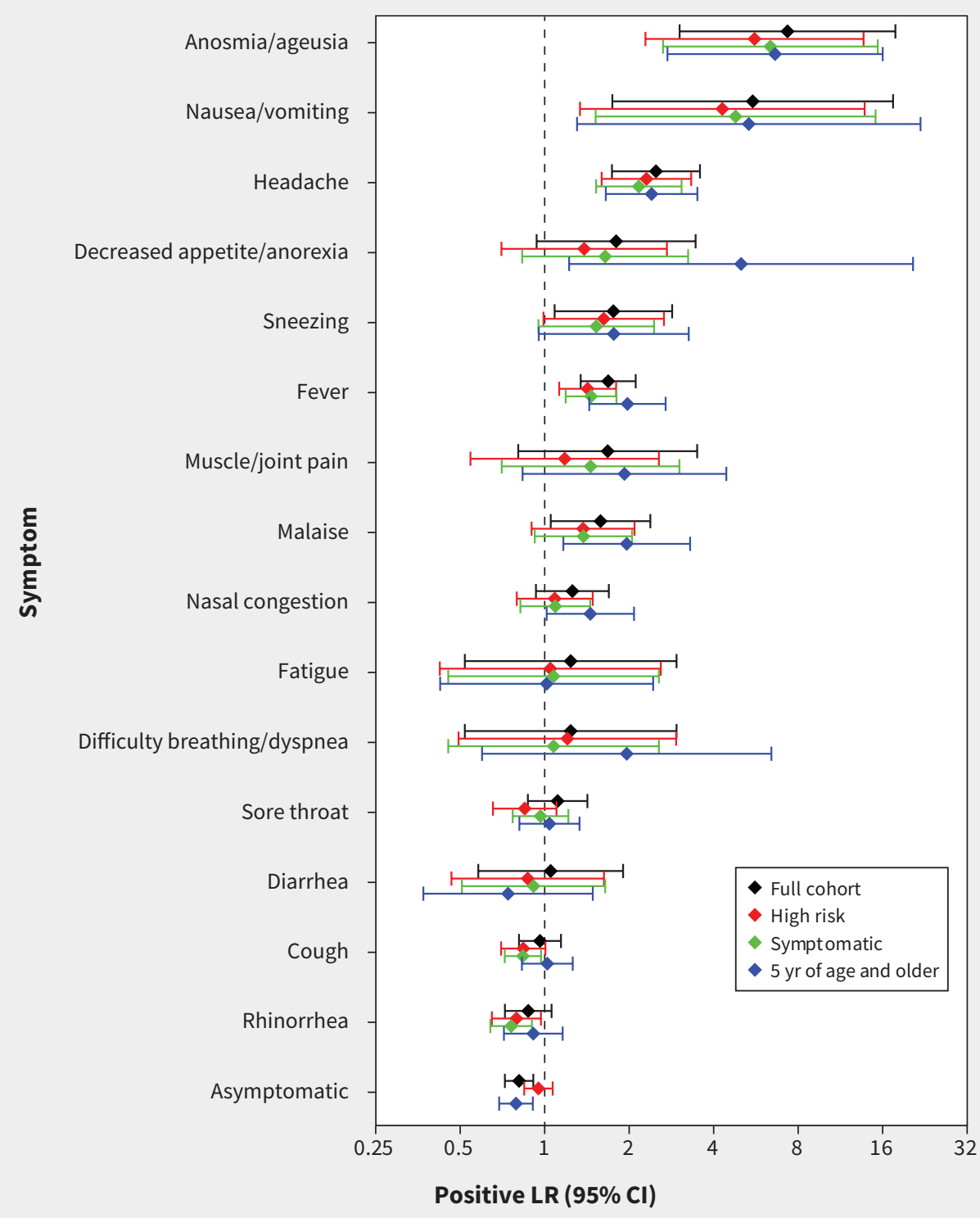

Figure 2: Positive likelihood ratios (LRs) for symptoms associated with positive results for severe acute respiratory syndrome coronavirus 2 (SARS-CoV-2) swabs in children in Alberta. Estimates of positive LRs and associated 95\% confidence intervals (Cls) are shown for the full cohort (black), those children identified as having a high risk of exposure through contact tracing (red), those with at least $1 \mathrm{symptom}$ (green) and those aged 5 years or older (blue).

$42 \%,{ }^{15} 70 \%{ }^{4}$ and $74 \% .{ }^{16}$ Our community-based cohort likely includes milder cases of disease relative to hospital-based cohorts, accounting for these lower frequencies. In contrast, rhinorrhea was more frequent in our cohort (19\%) than a hospitalbased cohort (8\%), ${ }^{15}$ although this was not consistent across studies. ${ }^{16}$ Our symptom frequency is also lower than recent reports from the Public Health Agency of Canada (PHAC) about symptoms in Canadian children with COVID-19 (where cough was reported in $49 \%$, fever in $46 \%$ and rhinorrhea in $40 \%$ ), but the PHAC data reported symptoms from only $26 \%$ of cases, with wide variations among jurisdictions. ${ }^{14}$

We also found that $36 \%$ of children who tested positive for SARS-CoV-2 reported no symptoms, which is similar to the $27.2 \%$ of children with SARS-CoV-2 infection who were asymptomatic in 
Table 3: Baseline characteristics and symptoms in Alberta children tested for severe acute respiratory syndrome coronavirus 2 infection because of a high-risk exposure

\begin{tabular}{|c|c|c|c|c|}
\hline Variable & $\begin{array}{c}\text { No. }(\%) \text { in patients with } \\
\text { positive SARS-CoV-2 } \\
\text { Swab* } \\
n=1515\end{array}$ & $\begin{array}{c}\text { No. (\%) in patients with } \\
\text { negative SARS-CoV-2 } \\
\text { swab* } \\
n=476\end{array}$ & $\begin{array}{l}\text { Unadjusted OR } \\
\quad(95 \% \mathrm{CI})\end{array}$ & $\begin{array}{l}\text { Unadjusted positive } \\
\text { for SARS-CoV-2 } \\
\text { infection } \\
(95 \% \mathrm{CI})\end{array}$ \\
\hline \multicolumn{5}{|l|}{ Demographic characteristic } \\
\hline Age, yr; mean \pm SD & $9.1 \pm 5.2$ & $8.5 \pm 5.3$ & NA & NA \\
\hline Age $0-4$ yr & $361(23.8)$ & $143(30.0)$ & $0.73(0.58-0.92)$ & $0.79(0.67-0.93)$ \\
\hline Age 5-12 yr & $672(44.4)$ & $199(41.8)$ & $1.11(0.90-1.37)$ & $1.06(0.94-1.20)$ \\
\hline Age $13-17 \mathrm{yr}$ & $482(31.8)$ & $134(28.2)$ & $1.19(0.95-1.49)$ & $1.13(0.96-1.33)$ \\
\hline Male sex & $755(49.8)$ & $254(53.4)$ & $0.87(0.71-1.07)$ & $0.93(0.85-1.03)$ \\
\hline \multicolumn{5}{|l|}{ Symptom } \\
\hline Anosmia/ageusia & $89(5.9)$ & $5(1.1)$ & $5.88(2.37-14.56)$ & $5.59(2.29-13.69)$ \\
\hline Nausea/vomiting & $41(2.7)$ & Suppressed as count $<5$ & $4.39(1.35-14.23)$ & $4.29(1.34-13.80)$ \\
\hline Headache & $220(14.5)$ & $30(6.3)$ & $2.53(1.70-3.75)$ & $2.30(1.60-3.33)$ \\
\hline Decreased appetite/anorexia & $44(2.9)$ & $10(2.1)$ & $1.39(0.70-2.79)$ & $1.38(0.70-2.73)$ \\
\hline Sneezing & $93(6.1)$ & $18(3.8)$ & $1.66(0.99-2.79)$ & $1.62(0.99-2.66)$ \\
\hline Fever or feverish chills & $326(21.5)$ & $72(15.1)$ & $1.54(1.16-2.03)$ & $1.42(1.13-1.80)$ \\
\hline $\begin{array}{l}\text { Muscle/joint pain (myalgia, } \\
\text { arthralgia, muscular or joint pain) }\end{array}$ & $30(2.0)$ & $8(1.7)$ & $1.18(0.54-2.60)$ & $1.18(0.54-2.55)$ \\
\hline Malaise & $109(7.2)$ & $25(5.3)$ & $1.40(0.89-2.19)$ & $1.37(0.90-2.09)$ \\
\hline Nasal congestion & $159(10.5)$ & $46(9.7)$ & $1.10(0.78-1.55)$ & $1.09(0.80-1.48)$ \\
\hline Fatigue & $20(1.3)$ & $6(1.3)$ & $1.05(0.42-2.62)$ & $1.05(0.42-2.59)$ \\
\hline Difficulty breathing/dyspnea & $23(1.5)$ & $6(1.3)$ & $1.21(0.49-2.98)$ & $1.20(0.49-2.94)$ \\
\hline Sore throat & $181(11.9)$ & $67(14.1)$ & $0.83(0.61-1.12)$ & $0.85(0.65-1.10)$ \\
\hline Diarrhea & $36(2.4)$ & $13(2.7)$ & $0.87(0.46-1.65)$ & $0.87(0.47-1.63)$ \\
\hline Cough & $323(21.3)$ & $121(25.4)$ & $0.80(0.63-1.01)$ & $0.84(0.70-1.01)$ \\
\hline Rhinorrhea & $265(17.5)$ & $105(22.1)$ & $0.75(0.58-0.97)$ & $0.79(0.65-0.97)$ \\
\hline Chest pain & $9(0.6)$ & Suppressed as count $<5$ & NA & NA \\
\hline Conjunctivitis & $8(0.5)$ & Suppressed as count $<5$ & NA & NA \\
\hline Asymptomatic & $638(42.1)$ & $211(44.3)$ & $0.91(0.74-1.12)$ & $0.95(0.85-1.07)$ \\
\hline
\end{tabular}

Note: $\mathrm{Cl}=$ confidence interval, $\mathrm{LR}=$ likelihood ratio, $\mathrm{NA}=$ not applicable, $\mathrm{OR}=$ odds ratio, $\mathrm{SARS}-\mathrm{CoV}-2$ = severe acute respiratory syndrome coronavirus 2 , SD = standard deviation. ${ }^{\star}$ Unless specified otherwise.

the most recent data from $\mathrm{PHAC}$ and the $27 \%$ reported in a preprint analysis involving school children in Switzerland. ${ }^{14,17}$ It is important to note that this is likely an underestimation of the true prevalence of asymptomatic SARS-CoV-2 infection, as those without symptoms are much less likely to seek testing than those with symptoms. Our findings that many viral symptoms in children are similarly prevalent in those with negative test results as those with positive test results also mirrors the findings presented in the preprint analysis of the Swiss cohort. ${ }^{17}$

Despite the clinical presentation differing among age groups (adults versus children), many of the symptoms we found to be strongly associated with a positive result for an RT-PCR swab for SARS-CoV-2 infection in children are similar to those described in a comparable outpatient adult population. ${ }^{18}$ Under revision anosmia/ ageusia was the strongest predictor in both adults and children, although its frequency and the magnitude of the positive LR were smaller in children. In contrast, headache had a higher PLR for a positive result for a SARS-CoV-2 swab in children, which is important to be aware of when screening children for possible infection. It is worth highlighting that most symptoms associated with SARS-CoV-2 positivity were uncommon in children, and would therefore have poor sensitivity in a potential screening test. For example, among symptoms predictive of a positive result for a SARS-CoV-2 swab, fever was the most frequently observed in patients with a positive test result, affecting only $26 \%$ of children.

A strength of our study was the community-based cohort of patients, which provided a more complete picture of the clinical presentation of children across the range of disease severity rather than being limited to children who presented to the emergency department or were admitted to hospital. Containing 
transmission of SARS-CoV-2 in pediatric settings is important to protect child health and safety and to minimize the spread of disease to the wider community. Given that certain healthmitigating behaviours (e.g., wearing masks and physical distancing) pose unique challenges with young children, monitoring for symptoms suggestive of SARS-CoV-2 infection before children enter a school or daycare setting may help reduce the chance of disease transmission. Although our results suggest that certain symptoms may be useful in identifying possible SARS-CoV-2 infections, future studies that either employ population-based methods or involve a representative sample of children who had a negative result on a SARS-CoV-2 swab (i.e., not just those identified through contact tracing) will add useful information.

\section{Limitations}

Our study has some notable limitations. We did not have information on symptoms for most of the children with negative RT-PCR swab results in Alberta. Alberta Public Health uses the CDOM database to specifically track communicable disease cases and their contacts, thus individuals who presented to a testing site with symptoms but had a negative result would not have been contacted by Alberta Public Health to have the complete symptom questionnaire collected. Thus, the negative cases in our sample were identified through contact tracing of children with high-risk exposures. The inclusion of all positive cases and only a select group of negative ones is a source of potential bias in our sample. We sought to mitigate this bias by emphasizing positive LRs rather than ORs or positive predictive values and performing a sensitivity analysis that restricted the positive cohort to those identified as high risk through contact tracing, and the results were similar (Figure 2); however, this limitation should be kept in mind when considering whether our results can be generalized to the larger population of all children tested for SARS-CoV-2 infection. We also did not have any information on symptom status for children who had SARS-CoV-2 infection but did not undergo testing. This may explain why children younger than 5 years of age were less likely to test positive for SARS-CoV-2 - as they may merely have been less likely to have received a swab based solely on symptoms without perceived risk. As testing criteria in Alberta evolved with the public health response in the province over the time period of our study, this could have affected the extent to which asymptomatic children were screened. Furthermore, symptoms were self-reported, which carries a risk of underreporting of less well publicized symptoms, and younger children may have been less able to fully describe their symptoms. Most symptom questionnaires were completed at the time of initial contact with the Alberta Public Health team; although CDOM records could be updated subsequently, we cannot verify how frequently this occurred. We did not have any information on seasonal allergies or asthma diagnoses in the children who were tested, which could have led to misattribution of symptoms. Finally, It should be acknowledged that, as with any study, some true associations might have been missed owing to insufficient power.

\section{Conclusion}

Because more than one-third of pediatric patients who test positive for SARS-CoV-2 infection exhibit no symptoms, identifying children who are likely to be infected is challenging. Our study highlights certain symptoms that might be useful in predicting which children have SARS-CoV-2 infections. Specifically, altered smell or taste, nausea/vomiting, headache and fever were the only symptoms strongly associated with a positive result for a swab test in all of our analyses. Many other influenza-like symptoms (such as cough, rhinorrhea and sore throat) were as common, or more common, in children who tested negative for SARS-CoV-2 infection. This information may be useful to those designing screening questionnaires for schools and daycares.

\section{References}

1. Mehta NS, Mytton OT, Mullins EWS, et al. SARS-CoV-2 (COVID-19): What do we know about children? A systematic review. Clin Infect Dis 2020 May 11 [Epub ahead of print]. doi: 10.1093/cid/ciaa556.

2. Li Q, Guan X, Wu P, et al. Early transmission dynamics in Wuhan, China, of novel coronavirus-infected pneumonia. N Engl J Med 2020;382:1199-207.

3. Wu Z, McGoogan JM. Characteristics of and important lessons from the coronavirus disease 2019 (COVID-19) outbreak in China: summary of a report of 72314 cases from the Chinese Center for Disease Control and Prevention. JAMA 2020;323:1239-42.

4. Swann OV, Holden KA, Turtle L, et al. Clinical characteristics of children and young people admitted to hospital with COVID-19 in United Kingdom: prospective multicentre observational cohort study. BMJ 2020;370:m3249.

5. Bi Q, Wu Y, Mei S, et al. Epidemiology and transmission of COVID-19 in 391 cases and 1286 of their close contacts in Shenzhen, China: a retrospective cohort study. Lancet Infect Dis 2020;20:911-9.

6. Ludvigsson JF. Systematic review of COVID-19 in children shows milder cases and a better prognosis than adults. Acta Paediatr 2020;109:1088-95.

7. Chen Z-M, Fu J-F, Shu Q, et al. Diagnosis and treatment recommendations for pediatric respiratory infection caused by the 2019 novel coronavirus. World J Pediatr 2020;16:240-6.

8. Yang Z-D, Zhou G-J, Jin R-M, et al. Clinical and transmission dynamics characteristics of 406 children with coronavirus disease 2019 in China: a review. J Infect 2020;81:e11-5.

9. Bixler D, Miller AD, Mattison CP, et al.; Pediatric Mortality Investigation Team. SARS-CoV-2-associated deaths among persons aged < 21 years: United States, February 12-July 31, 2020. MMWR Morb Mortal Wkly Rep 2020;69:1324-9.

10. Knuth DE. The art of computer programming: Vol. 3 - Sorting and searching. 2nd ed. Boston: Addison-Wesley Professional; 1998.

11. McGee S. Simplifying likelihood ratios. J Gen Intern Med 2002;17:646-9.

12. Spiegelhalter DJ, Knill-Jones RP. Statistical and knowledge-based approaches to clinical decision-support systems, with an application in gastroenterology. J R Stat Soc [Ser A] 1984;147:35-58.

13. Chan SF, Deeks JJ, Macaskill P, et al. Three methods to construct predictive models using logistic regression and likelihood ratios to facilitate adjustment for pretest probability give similar results. J Clin Epidemiol 2008;61:52-63.

14. Table 13-10-0781-01: Detailed preliminary information on confirmed cases of COVID-19 (Revised), Public Health Agency of Canada. Ottawa: Statistics Canada; 2020. Available: https://www150.statcan.gc.ca/t1/tbl1/en/tv.action?pid $=1310078101$ (accessed 2020 Oct. 13).

15. Lu X, Zhang L, Du H, et al.; Chinese Pediatric Novel Coronavirus Study Team. SARS-CoV-2 infection in children. N Engl J Med 2020;382:1663-5.

16. Chan JF-W, Yuan S, Kok K-H, et al. A familial cluster of pneumonia associated with the 2019 novel coronavirus indicating person-to-person transmission: a study of a family cluster. Lancet 2020;395:514-23.

17. Ulyte A, Radtke T, Abela IA, et al. Variation in SARS-CoV-2 seroprevalence in school-children across districts, schools and classes [preprint]. medRxiv 2020 Sept. 18. doi: 10.1101/2020.09.18.20191254.

18. McAlister FA, Whitten TA, King JA, et al. Which adults presenting for SARS-CoV-2 testing are most likely to have a positive swab? A population-based cohort of 15,132 adults from Alberta, Canada. Chest. In press. 
Competing interests: None declared.

This article has been peer reviewed.

Affiliations: Alberta Strategy for Patient Oriented Research Support Unit Data Platform and Provincial Research Data Services (King, Whitten), Alberta Health Services, Calgary Alta.; Alberta Strategy for Patient Oriented Research Support Unit Data Platform (Bakal, McAlister) and Provincial Research Data Services (Bakal), Alberta Health Services, Edmonton, Alta.; Division of General Internal Medicine (McAlister), University of Alberta, Edmonton, Alta.

Contributors: All of the authors conceived and designed the study. James King and Tara Whitten conducted the analysis and drafted the manuscript. Jeffrey Bakal and Finlay McAlister revised the manuscript critically for important intellectual content. All of the authors gave final approval of the version to be published and agreed to be accountable for all aspects of the work. James King and Tara Whitten contributed equally as co-first authors.

Funding: Finlay McAlister is funded by an Alberta Health Services Chair in Cardiovascular Outcomes Research, and this project was supported by the Alberta Strategy for Patient Oriented Research Support Unit.

Data sharing: The data set from this study is held securely in coded form at Alberta Health Services (AHS). Although data sharing agreements prohibit AHS from making the data set publicly available, access may be granted to those who meet prespecified criteria for confidential access. Please contact SPOR.DATA@ahs.ca for more information.

Content licence: This is an Open Access article distributed in accordance with the terms of the Creative Commons Attribution (CC BY-NC-ND 4.0) licence, which permits use, distribution and reproduction in any medium, provided that the original publication is properly cited, the use is non-commercial (i.e. research or educational use), and no modifications or adaptations are made. See: https://creativecommons.org/ licenses/by-nc-nd/4.0/

Acknowledgements: We thank Tanya Masson-McCrory, Clinical Educator for the Alberta Health Services Communicable Disease Outbreak Management (CDOM) program and the medical student volunteers who helped collect symptom data from patients included in the CDOM.

Disclaimer: This study is based in part on data provided by Alberta Health and Alberta Health Services. The interpretation and conclusions contained herein are those of the researchers and do not represent the views of the Government of Alberta or Alberta Health Services. Neither the Government of Alberta nor Alberta Health Services express any opinion in relation to this study.

Accepted: Nov. 9, 2020

Correspondence to: Finlay McAlister, finlay.mcalister@ualberta.ca 